\title{
Abnormal goblet cell glycoconjugates in rectal biopsies associated with an increased risk of neoplasia in patients with ulcerative colitis: early results of a prospective study
}

\author{
C R BOLAND, P LANCE, B LEVIN, R H RIDDELL, AND Y S KIM
}

From the Gastrointestinal Research Laboratory (151M2), and the Department of Medicine, Veterans Administration Medical Centre, and the University of California, San Francisco, California, and the Departments of Medicine and Pathology, University of Chicago School of Medicine, Chicago, Illinois

SUMmaRY A group of 18 patients with stable ulcerative colitis involving the entire colon for at least eight years was subjected to a biopsy of normal appearing rectal mucosa and followed prospectively over four years for the development of either dysplasia or cancer. Goblet cell glycoconjugate structure was examined in the rectal biopsies using fluorescein conjugated lectins. At the beginning of the study, 13 of the 18 patients had abnormalities of goblet cell mucin or cytoplasmic glycoconjugates in the rectal biopsies. Dysplasia subsequently developed in six and carcinoma in one of these patients. Among the five patients with normal lectin binding studies in the initial rectal biopsies, colonic dysplasia has subsequently developed in one. The abnormalities seen in the rectal goblet cells resembled in part those previously seen in immature and neoplastic colonic cells. The dysplastic tissues all contained the form of mucin which has been found in other neoplastic colonic tissues. This preliminary report after four years of prospective study suggests that abnormalities of glycoconjugate structure may be associated with, and may precede, neoplastic events in the setting of chronic ulcerative colitis.

- Patients with chronic ulcerative colitis have an increased risk of developing colonic cancer, especially when the disease is longstanding and involves the entire colon. ${ }^{1-3}$ These tumours are hard to identify at an early stage because the manifestations of ulcerative colitis may be difficult to distinguish from those of cancer, and gross mucosal distortions produced by the disease may mask a small neoplastic focus from detection by the radiologist or endoscopist. ${ }^{4}$ Diffuse abnormalities of the colon have therefore been sought that might enable the identification of malignant or premalignant changes at a potentially curable stage.

It has long been appreciated that a reduction in the amount of goblet cell mucus is characteristically seen in rectal biopsies from patients with ulcerative colitis. ${ }^{56}$ In addition, qualitative differences have been detected between the colonic mucus of healthy subjects and patients with ulcerative colitis. ${ }^{7}$ Our laboratory has found that fluorescein isothiocyanate

Address for correspondence: C Richard Boland MD. GI Unit. VA Medical Center. 2215 Fuller Road, Ann Arbor, MI 48105, USA.

Received for publication 10 February 1984
(FITC)-conjugated lectins are useful as probes of the carbohydrate structure of mucins, and that changes in the lectin binding characteristics reflect the state of differentiation and the presence of malignant transformation in colonic epithelial cells. ${ }^{8} 9$

It was decided, therefore, to study the goblet cell glycoconjugates in rectal biopsies of patients with stable, chronic ulcerative colitis in an effort to detect early signs of neoplastic change. A group of patients was followed prospectively for four years after an initial rectal biopsy from each had been studied with FITC-lectins. Those patients who subsequently developed neoplastic changes in the colon came predominantly from the group in which abnormalities of lectin binding had been detected at the beginning of the study.

\section{Methods}

PATIENTS

A group of 18 patients with chronic ulcerative colitis at high risk to develop neoplasia was selected, each 
with total ulcerative colitis for a minimum of eight years (range 8-34 years, median 20 years), and disease that was stable and free of neoplasia at the beginning of the study in 1979. All patients underwent rectal biopsies from a randomly selected site in the rectum $2-10 \mathrm{~cm}$ from the anus. The biopsies were fixed in Bouin's solution and embedded in paraffin. The biopsies were examined for pathological diagnosis and the presence of dysplasia (by RHR), coded, and sent to the University of California for study with FITC-lectins. None of the tissues was acutely inflamed. Five micron sections were cut, serially rehydrated, and incubated with $50 \mu \mathrm{l}$ of a commercially (Vector Laboratories, Burlingame, CA) obtained FITClectin solution at $200 \mu \mathrm{g} / \mathrm{ml}, \mathrm{pH} 7 \cdot 1$ for a period of 20 minutes followed by rinsing and mounting. ${ }^{8}$ Eight different FITC-lectins were used (Dolichos biflorus agglutinin (DBA), soybean agglutinin (SBA), peanut agglutinin (PNA), Bauhinia purpurea agglutinin (BPA), Ricinus communis agglutinin-1 (RCA-1), wheat germ agglutinin (WGA), concanavalin A (ConA) and Ulex europeus agglutinin-1 (UEA-1)) (see Table 1). Coincubation with inhibitory hapten sugars confirmed the labelling specificity of the lectins. ${ }^{8}$ The slides were examined under fluorescence microscopy by two

Table 1 Lectins used to study glycoconjuates in ulcerative colitis

$\begin{array}{ll}\text { Major } & \begin{array}{l}\text { Binding to } \\ \text { mucin in } \\ \text { normal } \\ \text { sugar } \\ \text { binding } \\ \text { specificity } \\ \text { biopsies } \\ (0-4+)\end{array}\end{array}$

independent observers (CRB and PL) and the labelling of goblet cell glycoconjugates was scored from 0 (absent) to 4+ (maximum fluorescence), and compared with findings previously obtained from normal colonic mucosa. ${ }^{810}$ Agreement in labelling was reached on all tissues. The patients were followed clinically for three years (by BL). Colonoscopy was performed annually and biopsies taken at $10 \mathrm{~cm}$ intervals from caecum to rectum to screen for neoplasia. Most of the patients were treated with sulphasalazine, and some required the intermittent use of steroids.

The code was broken in 1982 and the results of the lectin studies were compared with the clinical outcome for each patient. Additional tissues were obtained for lectin studies from four of the patients who developed dysplasia (A, C, M, and N).

The data were analysed using a $\chi^{2}$ contingency table.

\section{Results}

DATA OBTAINED USING FITC-LECTINS ON THE

INITIAL RECTAL BIOPSIES

The results of the labelling with four of the lectins (ConA, RCA-1, UEA-1, and WGA) were essentially the same as those found in the normal colon $^{810}$ (see Table 2). With the four other lectins (DBA, SBA, PNA, and BPA), however, differences were seen (Table 3). A marked reduction in the labelling of goblet cell mucin occurred in 5/18 with FITC-DBA and 8/18 with FITC-SBA (Figs. 1-3). A total of $9 / 18$ showed a reduction in labelling with either DBA or SBA, which require exposed GalNAc residues for binding. FITC-PNA produced an unusual form of labelling in $11 / 18$ of the biopsies in which glycoconjugates in the supranuclear region were labelled (Figs. 4 and 5). In only one biopsy was the goblet cell mucin also labelled by PNA. An increase in labelling of goblet cell mucin (compared with superficial biopsies from the normal colon) ${ }^{8}{ }^{10}$ was seen in 4/18 using FITC-BPA. Increased labelling of BPA was seen only in biopsies which also had abnormalities of lectin binding using DBA, SBA or

Table 2 Labelling of biopsies with ConA, RCA, UEA, and $W G A$, showing no significant difference between ulcerative colitic and normal colon ${ }^{\prime O}$

\begin{tabular}{lll}
\hline Lectin & Normal colon & Ulcerative colitis \\
\hline ConA & Variable; usually $0-2+$ & All $0-1+$ \\
RCA & $0-2+$ & $0-2+$ \\
UEA & Usually 0 & 0 \\
WGA & $4+$ & $4+$ \\
\hline
\end{tabular}


Table 3 FITC-lectin labelling data using $D B A, S B A$, $P N A$, and BPA - qualitative abnormalities detected in ulcerative colitis lectin labelling characteristics

\begin{tabular}{|c|c|c|c|c|c|c|}
\hline \multirow{2}{*}{ Patient } & \multirow{2}{*}{$\begin{array}{l}\text { Duration of } \\
\text { disease (yr) }\end{array}$} & \multicolumn{4}{|c|}{$\begin{array}{l}\text { Lectin labelling } \\
\text { characteristics }\end{array}$} & \multirow{2}{*}{$\begin{array}{l}\text { Clinical } \\
\text { outcome } \\
\text { during study }\end{array}$} \\
\hline & & $D B A$ & $S B A$ & $P N A$ & $B P A$ & \\
\hline A & 34 & $\ddagger$ & $\ddagger$ & $*$ & $\S$ & Dysplasia \\
\hline B & 32 & $\ddagger$ & $\ddagger$ & $\mathrm{n}$ & $\mathbf{n}$ & \\
\hline C & 27 & $\mathbf{n}$ & $\mathbf{n}$ & $\mathrm{n}$ & $\mathbf{n}$ & $\begin{array}{l}\text { Colectomy } \\
\text { (benign stricture) }\end{array}$ \\
\hline D & 25 & $\mathbf{n}$ & $\mathbf{n}$ & $*$ & $\mathbf{n}$ & \\
\hline $\mathrm{E}$ & 23 & $\mathbf{n}$ & $\mathrm{n}$ & $\mathbf{n}$ & $\mathrm{n}$ & \\
\hline $\mathbf{F}$ & 22 & $\mathbf{n}$ & $\mathrm{n}$ & $*$ & $\mathbf{n}$ & \\
\hline G & 21 & $\mathbf{n}$ & $\mathrm{n}$ & $\mathbf{n}$ & $\mathbf{n}$ & \\
\hline $\mathrm{H}$ & 21 & $\mathrm{n}$ & $\mathrm{n}$ & $\mathbf{n}$ & $\mathbf{n}$ & $\begin{array}{l}\text { Dysplasia; } \\
\text { colectomy }\end{array}$ \\
\hline I & 19 & $\mathrm{n}$ & $\mathbf{n}$ & $\mathbf{n}$ & $\mathbf{n}$ & \\
\hline $\mathbf{J}$ & 18 & $\mathbf{n}$ & $\ddagger$ & $*$ & $\mathbf{n}$ & \\
\hline $\mathbf{K}$ & 14 & $\ddagger$ & $\ddagger$ & $*$ & $\S$ & \\
\hline L & 13 & $\mathbf{n}$ & $\ddagger$ & $*$ & $\mathbf{n}$ & Dysplasia \\
\hline $\mathbf{M}$ & 13 & $\mathrm{n}$ & $\ddagger$ & $*$ & $\mathbf{n}$ & Dysplasia \\
\hline $\mathbf{N}$ & 13 & $\mathbf{n}$ & $\mathbf{n}$ & $*$ & $\mathbf{n}$ & Dysplasia \\
\hline $\mathrm{O}$ & 11 & $\ddagger$ & $\ddagger$ & $*$ & $\S$ & \\
\hline $\mathbf{P}$ & 11 & $\mathbf{n}$ & $\ddagger$ & $\mathbf{n}$ & $\mathbf{n}$ & \\
\hline Q & 9 & $\ddagger$ & $\mathrm{n}$ & $*$ & $\mathbf{n}$ & Dysplasia \\
\hline $\mathbf{R}$ & 8 & $\mathrm{n}$ & $\mathbf{n}$ & $\dagger$ & $\S$ & Adenocarcinoma \\
\hline
\end{tabular}

$\mathrm{n}=$ labelling identical to that in normal colon, ${ }^{*}=$ labelling occurs in the supranuclear glycoconjugates (?Golgi region), $\dagger=$ labelling in the supranuclear region and goblet cell mucin, $\ddagger=$ a marked reduction in or loss of labelling compared with the normal colon, $\S=$ substantially increased compared with normal colon.

PNA. A total of $13 / 18$ of the biopsies showed at least one abnormality of lectin binding; abnormalities with more than one lectin were found in $9 / 18 ; 4 / 18$ showed a single aberration, and in $3 / 4$ of these cases the single abnormality occurred with PNA (Table 4).

\section{CLINICAL OUTCOME}

All 18 patients have been followed clinically for the four year study period. During this time, serial colonoscopic biopsies have revealed the development of dysplasia (determined independently by

Table 4 Summary of abnormal labelling of goblet cell glycoconjugates

\begin{tabular}{|c|c|c|}
\hline Lectin & $\begin{array}{l}\text { Labelling in } \\
\text { normal colon }\end{array}$ & $\begin{array}{l}\text { Labelling in } \\
\text { ulcerative colitis colon }\end{array}$ \\
\hline DBA & $4+$ & Reduced to $0-2+$ in $5 / 18$ \\
\hline SBA & $4+$ & Reduced to $0-2+$ in $8 / 18$ \\
\hline PNA & 0 & $\begin{array}{l}\text { Supranuclear labelling in } 11 / 18 \\
\text { Goblet cell mucin labelling } \\
\text { in } 1 / 18\end{array}$ \\
\hline BPA & $0-2+$ & $\begin{array}{l}\text { Increased labelling to } \\
3-4+\text { in } 4 / 18\end{array}$ \\
\hline
\end{tabular}

RHR) in six patients (A, H, L, M, N, and Q; see Tables 3 and 5). One patient underwent a colectomy for a stricture which proved to be benign (patient C). One patient was found to have a carcinoma of the transverse colon two years into the study period (patient R).

Six of the seven patients who developed dysplasia or carcinoma came from the subset of 13 in whom abnormalities of goblet cell glycoconjugates had been detected in the initial biopsy at the beginning of the study. Five of the six had abnormal labelling with more than one lectin. The patient who underwent a colectomy for a stricture (patient $\mathrm{C}$ ) had no neoplasia upon careful examination of the resected specimen, and his rectal biopsy had shown normal lectin binding. Dysplasia has developed in the caecum of one patient who had normal lectin binding studies at the initial biopsy (patient $\mathrm{H}$ ). Because of progression of the dysplasia, he underwent a colectomy and no carcinoma was found in the resected specimen. One rectal biopsy showed labelling of supranuclear glycoconjugates and goblet cell mucin by FITC-PNA (Fig. 6). This patient (R) developed carcinoma two years after the initial rectal biopsy. No patient died or developed fulminant disease during the study period.

$\chi^{2}$ analysis of the results using a two by two contingency table to test the association between the presence of PNA-binding glycoconjugates in the rectal biopsy and neoplasia gave a $\chi^{2}=2.91$, which corresponds to $0 \cdot 10>p>0 \cdot 05$.

\section{LECTIN STUDIES ON DYSPLASTIC TISSUES}

Colonic biopsies that showed dysplasia from four

Table 5 Development of neoplasia during clinical follow up

\begin{tabular}{llll}
\hline & $\begin{array}{l}\text { Neoplastic } \\
\text { Pevelopment }\end{array}$ & Location & $\begin{array}{l}\text { Time } \\
\text { interval (yr) }\end{array}$ \\
\hline A & Dysplasia (mild) & tc & 2 \\
H & Dysplasia (mild) & $\begin{array}{l}\text { caecum, ac, dc } \\
\text { (severe only }\end{array}$ & 2 \\
& Dysplasia (severe) & in caecum) & \\
& rectum & 1 \\
L & Dysplasia (mild) & - & 2 \\
& No dysplasia & rectum & 3 \\
M & Dysplasia (mild) & rectum & 3 \\
N & Dysplasia (mild) & rectum & initial biopsy \\
& Dysplasia (borderline) & rectum & 2 \\
& Dysplasia (mild) & rectum, tc & 3 \\
& Dysplasia (mild) & tc & 3 \\
Q & Dysplasia-associated mass & rectum & 1 \\
R & Dysplasia (mild) & tc & 2 \\
& Adenocarcinoma, & & \\
\hline
\end{tabular}

tc $=$ transverse colon, ac $=$ ascending colon, $\mathrm{dc}=$ descending colon. 


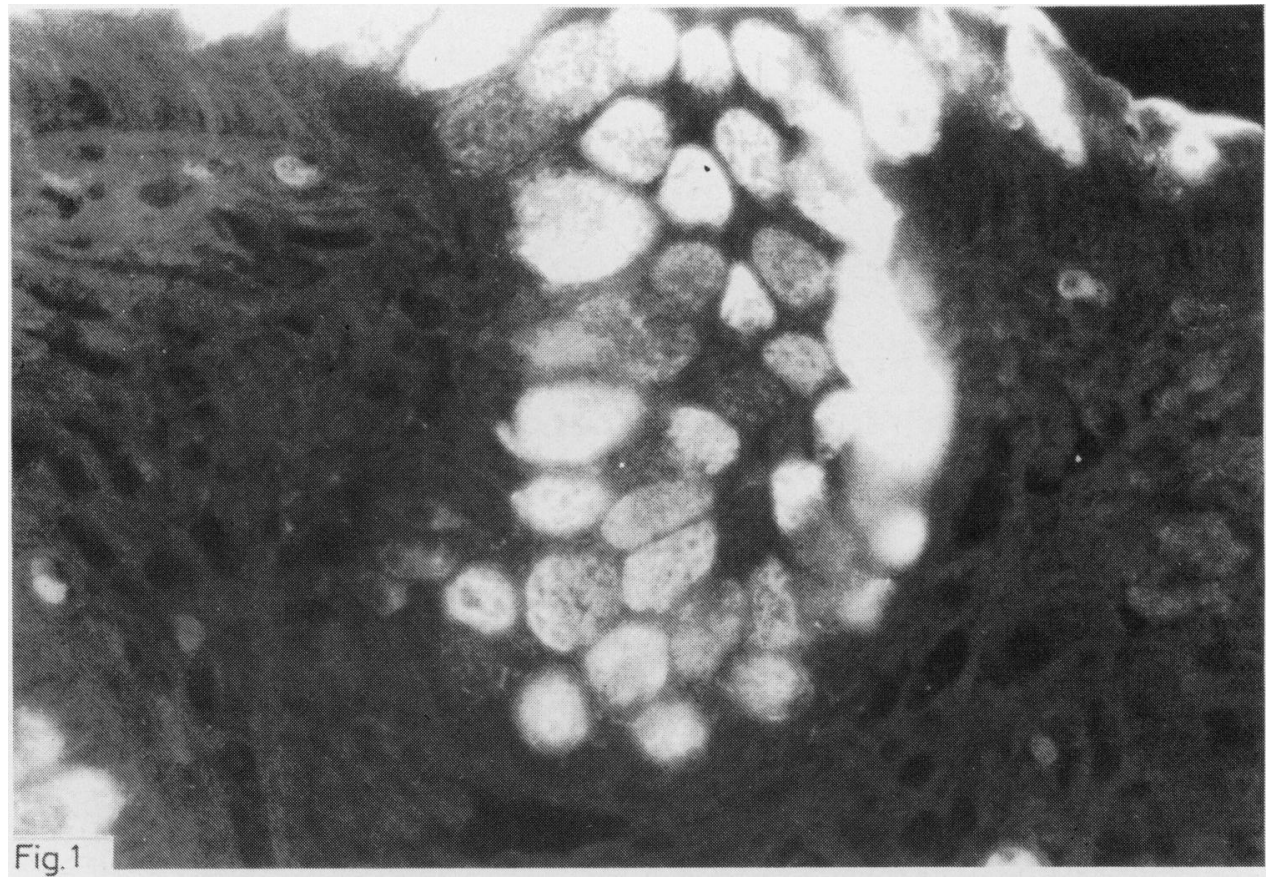

Fig. 1 FITC-SBA labelling of rectal biopsy material from patient I. Intense $(4+)$ fluorescent labelling of the goblet cell mucin similar to that seen in the normal colon. $(\times 125$ original magnification $)$.

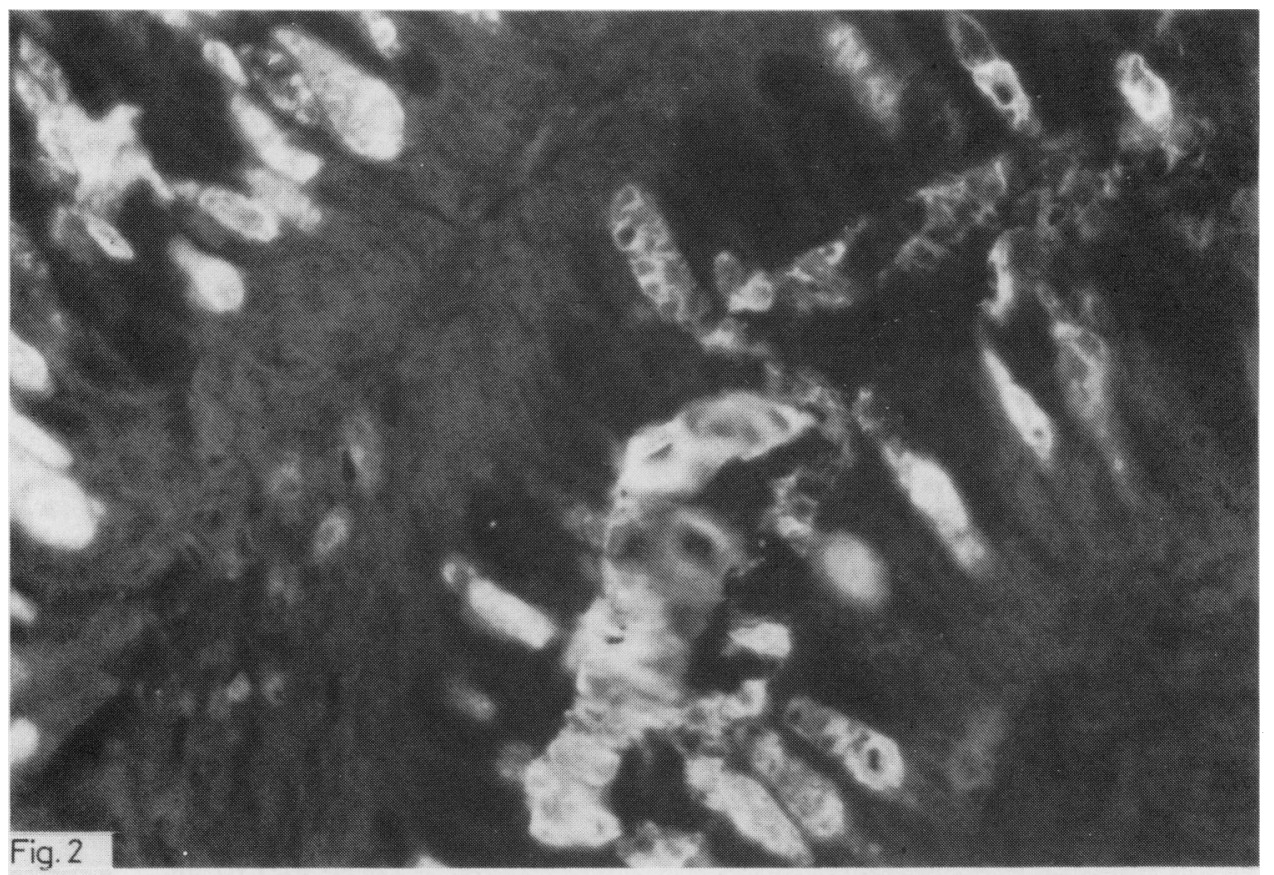

Fig. 2 FITC-DBA on rectal biopsy material from patient $J$, showing failure of labelling in some goblet cells, but with preservation of intense labelling in several remaining goblet cells. $(\times 125$ original magnification $)$. 

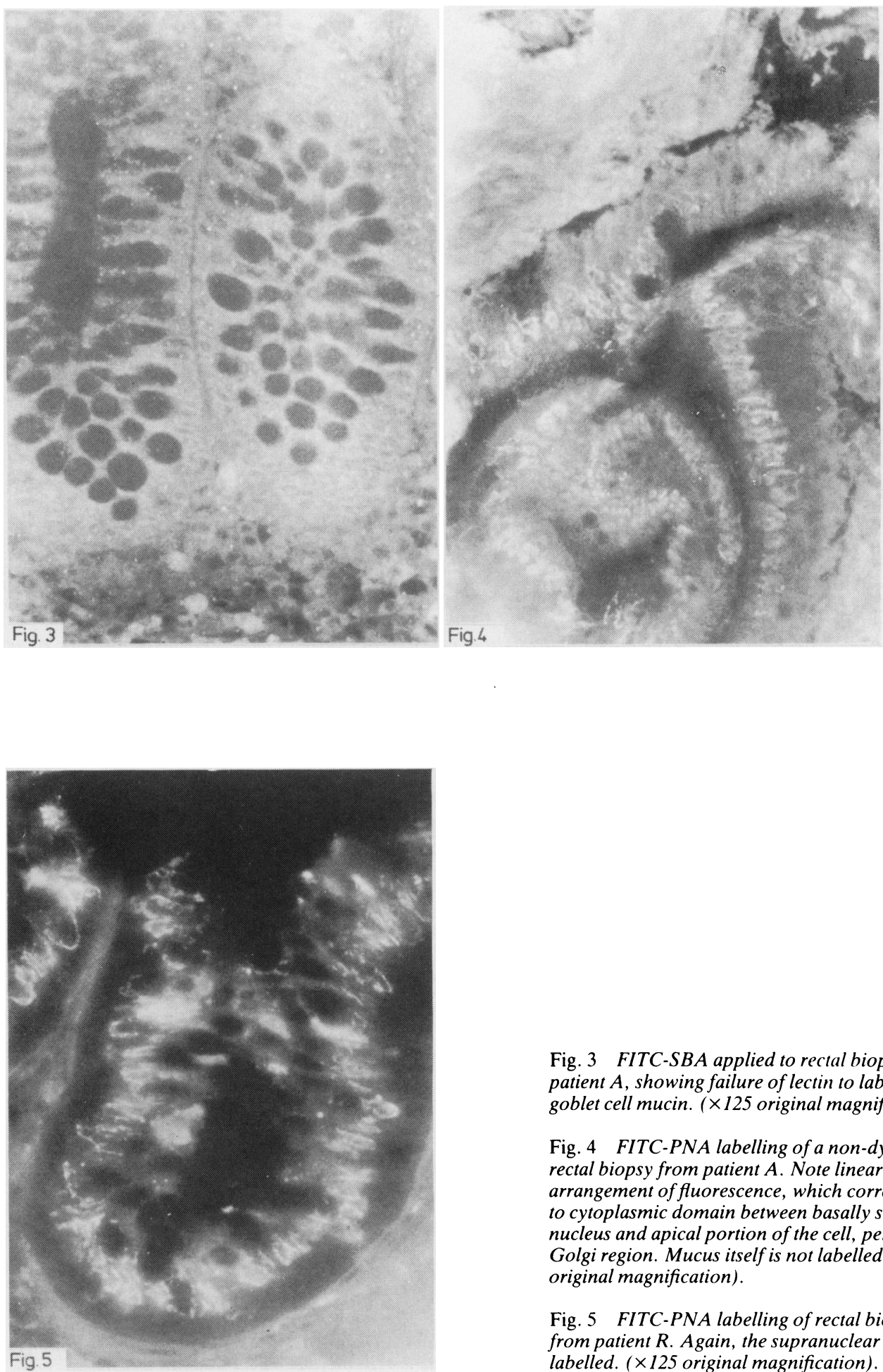

Fig. 3 FITC-SBA applied to rectal biopsy from patient $A$, showing failure of lectin to label any goblet cell mucin. $(\times 125$ original magnification $)$.

Fig. 4 FITC-PNA labelling of a non-dysplastic rectal biopsy from patient $A$. Note linear arrangement of fluorescence, which corresponds to cytoplasmic domain between basally situated nucleus and apical portion of the cell, perhaps Golgi region. Mucus itself is not labelled. $(\times 125$ original magnification).

Fig. 5 FITC-PNA labelling of rectal biopsy from patient $R$. Again, the supranuclear region is labelled. $(\times 125$ original magnification $)$. 


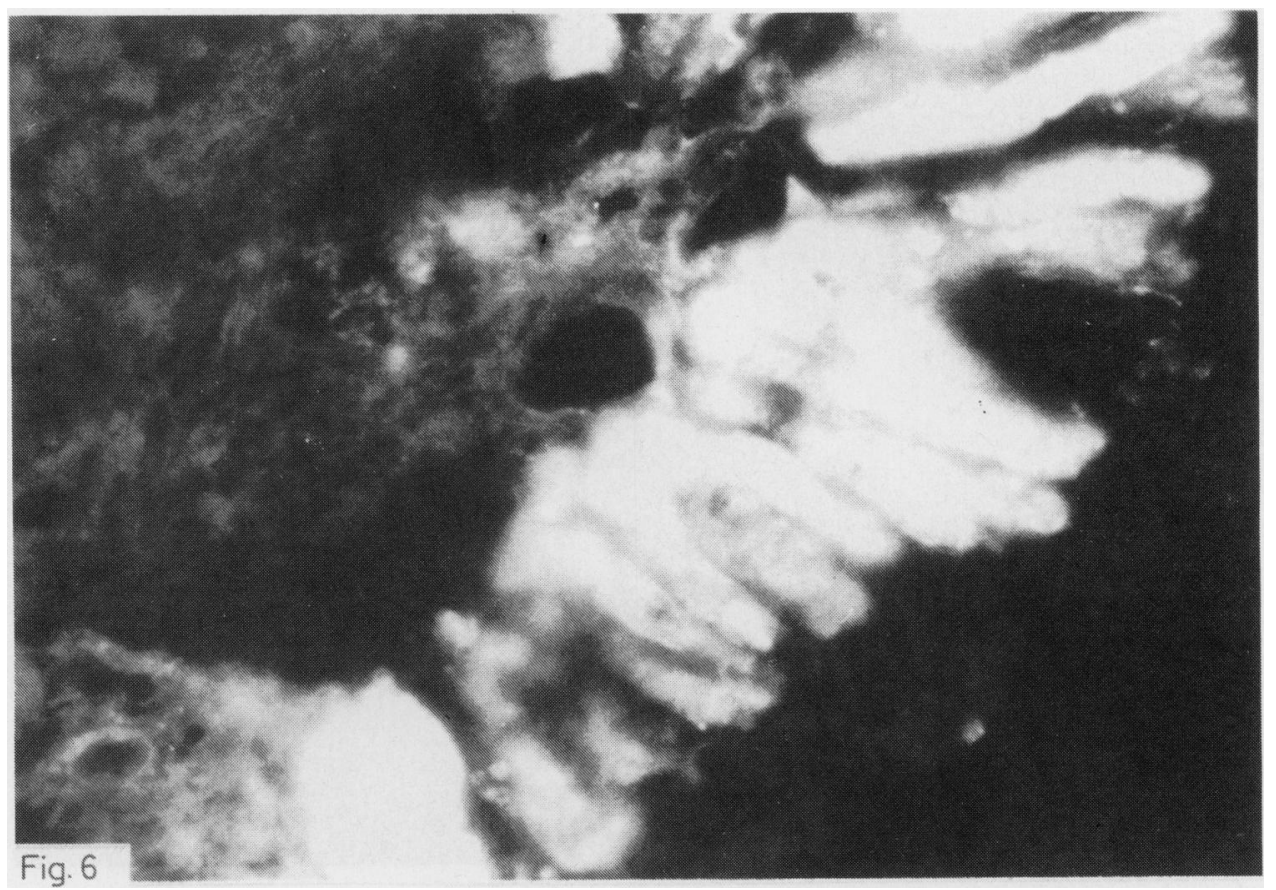

Fig. 6 FITC-PNA on rectal biopsy of patient $R$ (also in Fig. 5); note intense labelling of goblet cell mucin in this field. This was the only initial rectal biopsy to show labelling of goblet cell mucin with FITC-PNA, and this patient developed cancer two years later. $(\times 125$ original magnification $)$.

patients (Table 5) were studied with lectins, and PNA labelled either supranuclear glycoconjugates or goblet cell mucin in each case. In one case, patient $\mathrm{N}$, a 'dysplasia-associated mass lesion' was studied, revealing extensive labelling of the goblet cell mucin (Fig. 7).

\section{Discussion}

Colorectal cancer is one of the most serious complications of chronic ulcerative colitis, and the excess risk begins after approximately eight years of disease, rising progressively with time to $50-60 \%$ for patients who have disease of more than 30 years standing. ${ }^{1-3}$ We have previously reported the consistent presence of mucin which binds DBA but not PNA in normal specimens of colon. This observation has been confirmed in a larger study of normal colonic tissues (manuscript in preparation). Our data show that in a small cohort of patients with ulcerative colitis, after 8-34 years of disease (mean 20 years) the majority have developed qualitative abnormalities of goblet cell glycoconjugates in randomly obtained samples of rectal mucosa. These changes partially resembled those seen in immature goblet cells deep in the colonic crypt of the normal colon $^{10}$ (diminished binding by DBA and SBA, and increased binding by BPA), suggesting that the surface epithelial cells may be less mature in ulcerative colitis.

Six of our 13 patients with glycoconjugate abnormalities in the initial rectal biopsy have developed either dysplasia or cancer, but because of the same sample size a longer period of time is required to evaluate the predicative power of finding abnormal mucins in a rectal biopsy. Statistical analysis of the association between PNA-binding to the rectal biopsy and the subsequent development of neoplasia revealed that the association fell short of significance $(0 \cdot 10>p>0 \cdot 05)$. Although the group under study is a high risk subgroup of colitic patients (all with chronic pancolitis for 8-34 years), more time is necessary to identify all those who will eventually develop neoplasia. Because of the small cohort size and four year period of follow up, for the result to have been highly significant either more cases of neoplasia would have been required from the 'abnormal rectal mucin' group, or no cases of neoplasia would have been required from the 'normal rectal mucin' group. The dysplasia which 


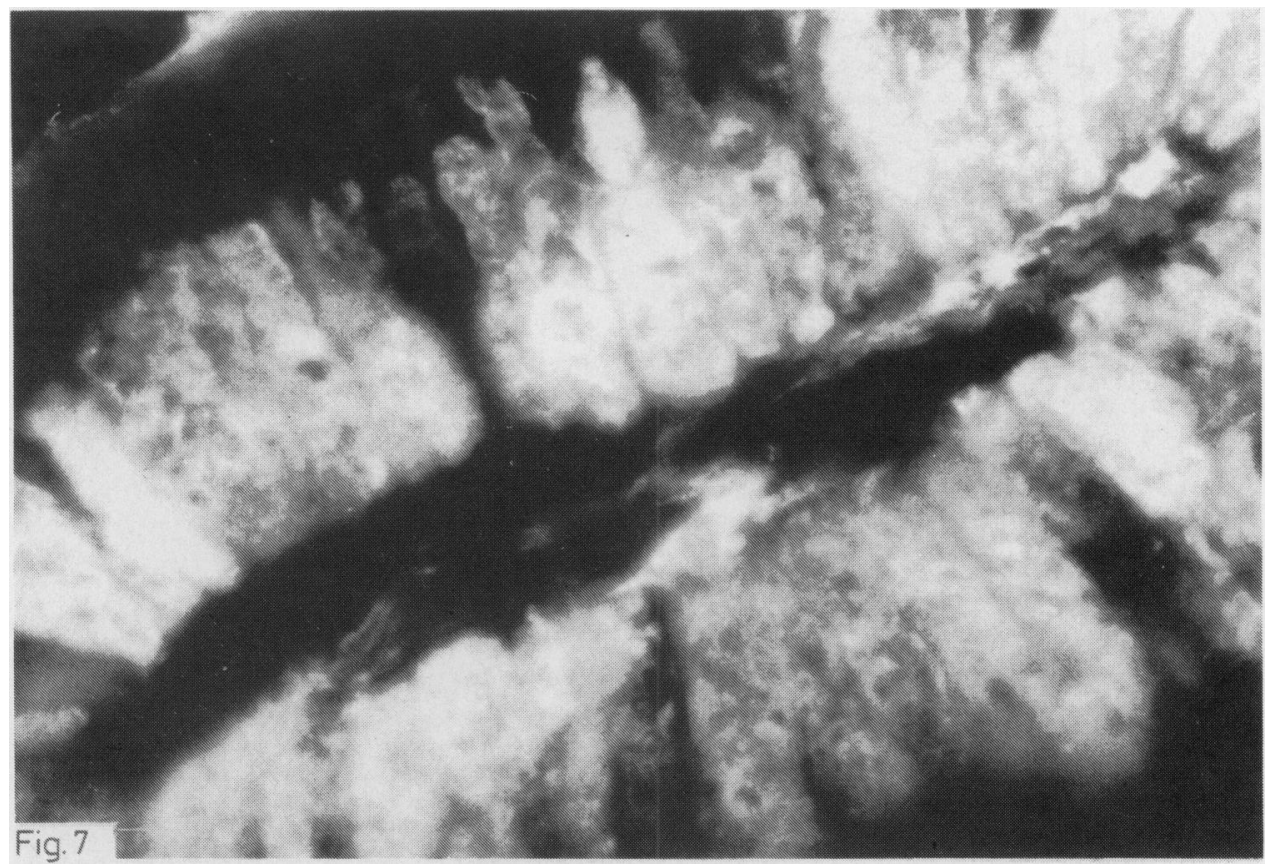

Fig. 7 FITC-PNA labelling of dysplastic biopsy specimen obtained from patient A two years after initial rectal biopsy. Note extensive labelling of goblet cell mucin, similar to that seen in Fig. $6 .(\times 200$ original magnification $)$.

occurred in a patient from the latter group was worst in the caecum and spared the rectum. This suggests that although the changes in goblet cell glycoconjugates may precede neoplasia in a given location, a single biopsy may be inadequate to assess the neoplastic risk of the entire colon.

Biochemically, the reduction in binding of DBA and SBA to goblet cell mucin indicates that there are fewer terminal, non-reducing GalNAc residues in the mucin oligosaccharide chains, which may be because of incomplete glycosylation of glycoproteins in the immature colonic epithelial cells. ${ }^{10}$ Analysis of the membrane glycoproteins from colonic cancer has previously revealed a marked reduction in total carbohydrate content, $\mathrm{ABO}$ blood group activity and glycosyltransferase activity compared with those from normal colon. ${ }^{11}$ Data from our laboratory obtained on mucins from colorectal carcinoma and colonic epithelium remote from cancers were consistent with the concept that the oligosaccharide chains are abnormal, and possibly incompletely synthesised in the transformed cells. This phenomenon might also be expected to result in the deletion of immunochemical characteristics expressed on the peripheral portion of the carbohydrate chain, thereby exposing structures normally hidden in the inner portion. ${ }^{10}$
The appearance of glycoconjugates which were bound by PNA is also seen in the mucin of colonic cancer as well as in adenomatous polyps and transitional mucosa. ${ }^{89}$ The presence of PNA binding in the supranuclear region but not in the goblet cell vacuole leaves the identity of these glycoconjugates open to question. The lectin may be labelling immature mucins in the Golgi region. An analysis of the binding specificity of PNA ${ }^{12}$ and a consideration of the composition of a typical mucintype oligosaccharide chain ${ }^{13}$ suggest that PNA would bind to a structure only found in the inner portion of the chain, supporting the concept that these changes reflect a defect in glycosylation of the mucin molecule. In support of this, Clamp et al have reported that the oligosaccharides extracted from the mucus of colectomy specimens from patients with ulcerative colitis and Crohn's disease of the colon contained only half as many carbohydrate units as were found in the mucus from normal colons obtained at necropsy. ${ }^{\text {? }}$

Using histochemical techniques, non-specific abnormalities of goblet cell mucin have been reported in the rectal biopsies of patients with ulcerative colitis. ${ }^{14}$ Ehsanullah et al have recently reported excess sialomucins in approximately half of the rectal biopsies of patients with ulcerative colitis, 
as well as most of the biopsies containing dysplasia, which parallels our own experience. ${ }^{15}$ This group and others have reported similar changes in transitional mucosa, ${ }^{16}$ adenomatous polyps, ${ }^{17}$ and familial polyposis coli. ${ }^{18}$ Other data, however, have suggested that these changes are not necessarily specific for neoplastic activity. ${ }^{19} 20$

The identification of a marker of colonic premalignancy in randomly obtained mucosal specimens has long been a goal of investigators in inflammatory bowel disease. Our data describe changes in the glycoconjugates of rectal mucosa in a small group of patients who have been studied over a short period of time. Until more patients are examined and the period of follow up is extended, the conclusions must remain preliminary. Abnormalities of mucin, however, are seen in dysplastic tissues which resemble those seen in cancer. Similar changes are seen in non-neoplastic rectal biopsies of many patients who later develop colorectal neoplasia in this setting. As dysplasia develops in a patchy manner in the colon, it may be necessary to use lectin binding studies on biopsy specimens taken throughout the colon and rectum to improve the sensitivity of the technique. A longer period of follow up is necessary to determine the specificity of these findings, and we will continue to follow this cohort prospectively. We feel that evaluating goblet cell mucin and cytoplasmic glycoconjugates with lectins is a promising approach in the assessment of neoplastic risk in ulcerative colitis.

This work was supported in part by USPHS Grants CA30667 (CRB), CA14905 (YSK), and a Research and Education Associateship of the Veterans Administration Medical Center (CRB). PL was the recipient of a Travelling Fellowship from the Peel Medical Research Trust of Great Britain. PL's current address is Department of Medicine, Brown University, Roger Williams General Hospital, Providence, RI.

This study was presented in part at the annual meeting of the American Gastroenterological Association in Chicago, Ill, May 1982.

The authors would like to thank Ms T Harrington for editing and typing this manuscript.

\section{References}

1 Edwards FC, Truelove SC. The course and prognosis of ulcerative colitis. Gut 1964; 5: 15-22.

2 Devroede GJ, Taylor WF, Sauer WG, Jackman RJ, Stickler GB. Cancer risk and life expectancy of children with ulcerative colitis. $N$ Engl J Med 1971; 285: 17-21.
3 Greenstein AJ, Sachar DB, Smith $\mathrm{H}$ et al. Cancer in universal and left sided ulcerative colitis. Factors determining risk. Gastroenterology 1979; 77: 290-4.

4 Butt JH, Lennard-Jones JE, Ritchie JK. A practical approach to cancer risk in inflammatory bowel disease. Med Clin N Am 1980; 64: 1203-20.

5 Hellstrom HR, Fisher ER. Estimation of mucosal mucin as an aid in the differentiation of Crohn's disease of the colon and chronic ulcerative colitis. Am J Clin Pathol 1967; 48: 259-68.

6 Filipe MI, Dawson IMP. The diagnostic value of mucosubstances in rectal biopsies from patients with ulcerative colitis and Crohn's disease. Gut 1970; 11: 229-34.

7 Clamp JR, Fraser G, Read AE. Study of the carbohydrate content of mucus glycoproteins from normal and diseased colons. Clin Sci 1981; 61: 229-34.

8 Boland CR, Montgomery CK, Kim YS. Alteration in human colonic mucin occurring with cellular differentiation and malignant transformation. Proc Natl Acad Sci USA 1982; 79: 2051-5.

9 Boland CR, Montgomery CK, Kim YS. A cancerassociated mucin alteration in benign colonic polyps. Gastroenterology 1982; 82: 664-72.

10 Boland CR, Kim YS. Lectin markers of differentiation and malignancy. In: Wohlman SR, Mastromarino AJ, eds. Markers of colonic cell differentiation. New York: Raven Press, 1984: 253-66.

$11 \mathrm{Kim}$ YS, Isaacs R, Perdomo JM. Alterations of membrane glycoproteins in human colonic adenocarcinoma. Proc Natl Acad Sci USA 1974; 71: 4869-73.

12 Lotan R, Skutelsky E, Danon D, Sharon N. The purification, composition, and specificity of the anti- $\mathrm{T}$ lectin from peanut (Arachis hypogaea). J Biol Chem 1975; 250: 8518-23.

13 Allen A. Structure and function of gastrointestinal mucus. In: Johnson LR, ed. Physiology of the gastrointestinal tract. New York: Raven Press, 1981: 617-39.

14 Greco V, Lauro F, Fabbrini A, Torsoli A. Histochemistry of the colonic epithelial mucins in normal subjects and in patients with ulcerative colitis. Gut 1967; 8: 491-6.

15 Ehsanullah M, Filipe MI, Gazzard B. Mucin secretion in inflammatory bowel disease: correlation with disease activity and dysplasia. Gut 1982; 23: 485-9.

16 Filipe MI, Branfoot AC. Abnormal patterns of mucus secretion in apparently normal mucosa of large intestine with carcinoma. Cancer 1974; 34: 282-90.

17 Filipe MI, Branfoot AC. Mucin histochemistry of the colon. In: Morson BE, ed. Pathology of the gastrointestinal tract. Berlin: Springer-Verlag, 1976: 143-78.

18 Filipe MI, Mughal S, Bussey HJ. Patterns of mucus secretion in the colonic epithelium in familial polyposis. Invest Cell Pathol 1980; 3: 329-43.

19 Ehsanullah M, Filipe MI, Gazzard B. Morphological and mucus secretion criteria for differential diagnosis of solitary ulcer syndrome and nonspecific proctitis. J Clin Pathol 1982; 35: 26-30.

20 Isaacson P, Attwood PRA. Failure to demonstrate specificity of the morphological and histochemical changes in mucosa adjacent to colonic carcinoma (transitional mucosa). J Clin Pathol 1979; 32: 214-18. 